\title{
Empowerment of women for health development: A global perspective
}

\author{
Snehendu B. Kar \\ Catherine Pascual \\ Kirstin Chickering \\ Tracy Hazelton
}

\section{Introduction}

This paper reviews two interrelated issues that affect health status and quality of life (QOL) in populations from a global perspective with special reference to women. These are: (1) the limits of conventional economic development (EDev) and health system reform (HSR) strategies in promoting health status and QOL for all. The first part of the paper reviews this issue; and (2) the importance of empowerment of women, concurrently with economic development (EDev) and health systems reform (HSR), for reducing persistent disparities in health and QOL across gender and ethnic groups. The second part of this paper reviews effective models and methods of women's empowerment movements and implications for promoting health and QOL in underserved and disadvantaged communities. This paper is based upon our on-going research on empowerment of women and mothers (WAM) for health promotion that grew from an earlier research project awarded to the senior author as an integral part of his Kellogg International Fellowship Program in Health (KIFPH) administered by the Michigan State University.

The objective of the Kellogg Project (parent project) was to develop "Indicators of Health Promotion" that could be used to monitor and evaluate effectiveness of health promotion and disease prevention (hereafter "Health Promotion") policies and interventions at the community level. Several powerful macro-systems determinants or exogenous factors (e.g. cultural, socio-economic, political, environmental) directly affect the (a) health status of populations and (b) scope and effectiveness of specific health policy and programs. Consequently health status change cannot be attributed to health programs alone. In addition, it often takes decades to achieve measurable impacts of a health program on health status of populations; we need "process indicators" to monitor progress and review policy towards the ultimate goal of achieving better health and quality of life at the community level. The Kellogg project focused on developing "process indicators" of health promotion that can be attributed to specific interventions at two levels: (i) Individual actions and (ii) societal actions. For instance, a reduction in the rate of cigarette smoking in a population represents an effective outcome of a lung cancer control program; reduction in smoking constitutes individual action for health promotion. However, individual action in turn is affected, both positively (e.g. marketing) and negatively (e.g. anti-smoking campaigns) by societal norms and actions; effective anti-smoking social action reduces both demands for and supply of cigarettes to current and potential smokers (e.g California's Proposition 99 which increased cigarette taxation and cost, smoking regulations, and anti-smoking campaigns). Therefore, the individual and societal actions that are known to prevent specific health risks that can be attributed to specific health promotion interventions represent effective indicators of health promotion policy and action. The project used a simplified "Delphi" technique to identify health promotion action indicators in several domains of health (physical, mental, and social) and quality of life. The Delphi panel included over 424 public health "experts" from forty-two countries. The results have been presented in detail elsewhere (Kar and Berkanovic, 1987; Kar et al, 1988; Kar, 1990; Kar, 2000).

A major finding of our parent study is that the Delphi experts identified "community participation" and "empowerment" as two important societal level "process indicators" of effective health promotion policy and intervention. At the same time, these experts did not identify effective empowerment methods or indicators for measuring empowerment. During the past two decades, community empowerment has emerged as a central theme in several global consensus documents that focused on health and human development. Notable among these include the Alma Ata Declaration (UNDP, 1999; Kar and Acalay, 2000); while the declaration did not specify "empowerment" as a strategy, per se, it emphasized the importance of active "community participation" for developing effective primary health care systems. Subsequently, while defining the mission and scope of health 
promotion, the Ottawa Charter for Health Promotion in 1986, aptly sums up the global consensus in these words "At the heart of this process (Health Promotion) is empowerment of the communities, their ownership and control of their own endeavors and destinies" (UNDP, 1999; Kar and Acalay, 2000). Recently, the Calcutta Declaration on the philosophy and scope of Public Health in the South-East Asian Region in the Twenty-first century, specifically emphasized human rights protection, empowerment of the disadvantaged, and reduction of poverty as core public health concerns (WHO/SEARO 2000). Recent global initiatives that focus on women's status and gender equity forcefully advocate for structural and cultural changes that empower women (e.g. CEDAW/UN, Beijing Platform of 1995, Beijing+5 Review in 2000). They further argue that initiatives for gender equity, including women's health development, must be based upon perspectives of women themselves. These initiatives should focus on empowerment of women through women's leadership development, equity in education and career opportunities, mobilization of resources from various agencies, including welfare systems for targeted legal and cultural reforms that are necessary for protecting women from various forms of injustice, violence and abuse that affect their health and QOL (e.g. missing women/femicide, female genital mutilation (FGM), intimate violence, sexual abuse, early/child marriage, reproductive risks, economic enslavement, dowry deaths, honor killing, and trafficking of women for sexual exploitation). Economic development and health systems reform alone will not address these and other threats to health and quality of life of women and families. Consequently, women's empowerment should be a centerpiece of all effective health and welfare systems.

In addition to these global consensus documents and other "right based" arguments, there are at least four important empirical justifications for empowering women for better health for all. First: in spite of a longer life span, women suffer a greater burden of health risks and abuses as discussed later. Second: women are the primary care givers in almost all families; often in many families they are the sole caregivers to their children and elderly. Third: evidence shows that compared to men, women spend their discretionary money and time differently with priorities on better health and quality of life of their children and family. Fourth: available studies (discussed later in this paper) suggest that, compared to men, targeted education of women regarding health, results in greater health benefits to their children and families. Thus empowerment of women not only affects health of women themselves, which is in itself is a valid justification, but it also results in greater benefits to their children, families, and communities. Empowerment is defined in this paper as a process through which individuals, communities and organizations gain control over issues and problems that concern them most, and take actions to prevent these threats and to achieve their priorities (Kar, 1990). The goal of an empowerment movement is, therefore, to enable the powerless to take proactive actions to prevent real threats and to promote their own goals.

\section{Factors and Forces affecting women's health welfare systems and quality of life (QOL)}

There is a consensus among the leading international organizations (e.g. UN, WHO, World Bank, and ILO) and development scholars that to achieve an effective change for better health and QOL for women, a dual approach is needed (UNDP, 1999; Kar and Acalay, 2000). These are: (1) reforming health and welfare systems that meet the specific and urgent needs of women (e.g. health care, day care), and (2) reforming socio-cultural systems that perpetuate gender inequalities which are the source of all day-to-day problems (e.g. equal opportunities for education, income, cultural practices and devaluation of women). These two approaches address what Moser (1987) identifies as two types of women's needs: "practical needs" and "strategic needs" respectively. The first approach focuses on day-to-day needs that are akin to the proverb, giving a fish to a starving person; while the second approach is giving a fishing rod and opportunities to fish. There is synergy between health systems, human development systems, and broader social reform. In recognition of this, the WHO has for decades argued that health development can not be fully accomplished by the health sector alone and has strongly advocated a multisectoral approach for reforming health and welfare systems to achieve better health for all. Welfare systems may be defined as enduring social organizations (both formal and non-formal) and practices (norms and actions) that affect health and well-being of populations. Development studies primarily focus on income, education, and health status as outcomes of effective welfare systems. For instance, United Nation's Human Development Reports use Human Development Index (HDI) to rank nations on levels of development. It combines average life expectancy at birth (health), educational attainment (adult literacy and combined school enrollment ratio), and standard of living (adjusted per capita income). More recently, gender equality, gender empowerment, and human poverty level have been included in order to assess the overall QOL or well being of nations. (Footnote 1) 


\section{Persistent Inequality}

A recent UNDP Human Development Report concludes that, in spite of phenomenal world economic growth between 1820 and 1992, "World inequalities have been rising steadily for nearly two centuries....the distance between the richest and poorest country was about 3 to 1 in 1820,11 to 1 in 1913, 35 to 1 in 1950,44 to 1 in 1973, and 72 to 1 in 1992" (UNDP, 1999). The richest $20 \%$ of the countries share $86 \%$ of the world GDP; the poorest $20 \%$ of the countries share $1 \%$ of the world GDP" (UNDP, 1999). The trend is towards the worse; the UNDP warns, "If global opportunities are not shared better, the failed growth of the last two decades will continue". On other indicators of Human Development Index (e.g. adult literacy, school enrollment, real GDP per capita income), Gender Development Index, Gender Empowerment Measures (GEM), the disparities between poor and rich nations are unacceptably large. (UNDP, 1999).

While men and women in large numbers and in many nations have benefited from various forms of social and technological developments, women continue to suffer from persistent inequalities in both poor and rich societies. In general, women carry most of the burden of caring for their children and domestic work. Empirical studies show that women also suffer most of the brunt of poverty and abuses due to persistent inequalities and relative powerlessness (Boserup, 1971; Sen, 1990; Tinker, 1990). Both in rich and poor nations, women suffer various forms of institutionalized injustice and abuse including: denial of basic needs (education and health care), feminization of poverty, unfair opportunities for employment, income, and leadership; sexual harassment and exploitation; physical mutilations and deaths, domestic violence; insufficient interest in gender-related issues in policy and research; and culturally conditioned practices that endanger women's health and quality of life (e.g FGM, dowry deaths, honor killing, early marriages). See Box 1.

Examples of inequality in richer countries include - income disparity between men and women for performing same work, insufficient understanding of women's needs associated with childbirth and care versus their employment, and women often being forced (due to lack of choice) to work in part-time and low-paid positions with long hours without health and retirement benefits (WHO, 1998; UNDP, 1999; World Bank, 2000). In a recent analysis, Nobel Laureate and development economist, Amartya Sen, sums up his thesis on development by the title of his latest book "Development as Freedom" (Sen, 1999). According to his analysis "Expansion of freedom is viewed, in this approach, both as the primary end and as the principal means for development"(Sen, 1999). Development is incomplete if individual freedom does not exist. An increase in individual freedom will contribute positively to economic development. Indeed, increased freedom, political participation, economic development, and social progress including better health, are all integral parts of development and they all interact with one another.

The framework of this paper holds that major social systems, including cultural, political, and religious systems influence our well-being through affecting four important and inter-related domains of welfare systems. These four systems are the proximal or immediate determinants of our health status and QOL. These are: (1) education, (2) income/employment, (3) health, and (4) justice (human rights and basic freedom). Consequently, this paper first raises important theoretical and practical issues inherent in and affecting these four sectors of welfare systems. Subsequently, it reviews lessons learned from 80 exemplary case studies of women's empowerment movements that enhanced their health and QOL. Welfare systems are conceptualized both as causal agents and as targets for reform. Both of the terms, QOL and well being, include health as an important component - they are used interchangeably.

\section{Wealth and Health}

The world has witnessed an unprecedented growth of wealth and technological revolution, especially during the second half of the 20th century. Concurrently, the overall health status in most nations has also improved (UNDP, 1999; WHO, 1999; World Bank, 1999). In spite of these and other technological achievements, the majority of the world's population, the women and the poor, continue to suffer from persistent inequalities (Footnote 2), which cause preventable harm to their health and quality of life. See Box 2. 
A direct relationship between human development and health status has been well established by numerous reports and data sets by WHO (Worlds Health Reports), UNDP (Human Development Reports), World Bank, UNESCO, UNICEF, and individual scholars (Boserup, 1971; Sen, 1990, Tinker, 1990). In Table 1 we compare selected health and QOL indicators of the ten highest and ten lowest countries ranked by Human Development Index (UNDP, 1999). Human development is significantly and positively related with life expectation at birth, female and adult literacy, school enrolment, family planning, and public expenditure on education and health. It is negatively related with high fertility rate, infant mortality, and maternal mortality (see Table 1).

Other analyses show that the health status of the population, reflected for example in health of workers, significantly affects economic productivity (WHO, 1996). Better health of populations affects economic productivity through several processes; it (1) reduces production losses due to worker's ill health, (2) increases human capital by increasing the proportion of an educated public (through increased enrollment of children in schools), (3) frees up resources otherwise spent on treatment of diseases for other developmental projects, and (4) increases national wealth by making available natural resources and cultivatable land previously not accessible due to persistent epidemics and endemic risks (WHO, 1996; ILO, 1998).

\section{Mortality}

Women in poor nations often pay a stiff price for persistent inequality with their lives and bodies. Maternal mortality and missing women are tragic indicators of preventable deaths among poor women. The range of maternal mortality across the world today is very large. At the same time, several poor countries with lower overall level of human development (HDI rank) have a lower level of maternal mortality than countries which rank higher on HDI. For instance, Malawi ranks 159 among a total of 174 countries and Nepal ranks 144 on HDI ranking by the UNDP. Yet maternal mortality rate in Malawi is about one-third the rate in Nepal (569 and 1,500 respectively) (UNDP, 1999).

One powerful indicator of systematic neglect and abuse of women in various cultures is the estimate of "missing women" or number of women who have died but would be expected to live if they had received the same levels of food and basic health care as the men in their societies. Biologically, women are believed to be "hardier" than men, and under normal circumstances, the number of female births is slightly higher than the number of male births. Consequently, in a society with an equal chance for survival for girls and boys, there should be more adult women than men, but this is not always the case. Globally, the estimate of missing women is over 100 million (Sen, 1999). Other evidence indicates that despite a country's low GNP, life expectancy can be quite high. As an example, in the state of Kerala (India) the GNP is less than $\$ 500$ dollars per person while the average life expectancy is over 72 years. Conversely, Gabon has a per capita income eight times higher than Kerala, nearly $\$ 4,000$ per person, but life expectancy in Gabon is only 52 years. Thus overall economic development, in itself, is not the primary cause of these differences in mortalities and burden of diseases between and within countries. Rather, a better distribution of welfare services and specifically women's empowerment through female literacy, employment, fairness, and access to health care would provide better mechanisms for improving health status (Sen, 1999; WHO, 1999).

\section{Morbidity}

In general, women live longer than men, they also report higher prevalence rates of illness and psychological distress. In many developing and patriarchal societies, the presumed "biological advantage of the majority of women is entirely cancelled out by their social disadvantage, offering a sharp reminder that economic development alone will not necessarily allow women greater opportunity to flourish" (WHO, 1998). The example of high life expectancy in Kerala discussed above, demonstrates that while wealth may affect disease burden and life expectancy, equitable distribution of wealth and welfare services has a greater effect on health (measured by life expectancy) in developing countries (World Bank, 1999; Harvard University, 2000). In spite of higher life expectancy, women are more likely to suffer and die from osteoporosis, diabetes, hypertension, arthritis, most immune disorders and psychological distress (WHO, 1998). There are also significant differences in the leading causes of disease burden (measured by disability adjusted life year or DALY) between women in developed and 
developing countries. Contrary to popular perception, five psychiatric disorders significantly outweigh burden of disease from all other (infectious and chronic) diseases combined in both developed and developing countries (see Figure 1.

These diseases, especially unipolar major depression, are also important sources of disease burden among women in developing and developed countries. As expected, TB, iron-deficiency anemia, pregnancy related complications and abortions take much higher tolls in developing countries. Some of the differences in morbidity and mortality between women and men are biologically linked. Reproductive and pregnancy risks are unique to women. It is estimated that over 80,000 women die each year due to unsafe abortions, which could be averted if safe contraceptives were available to them (WHO, 1995). Women live longer than men, which means that they have longer period of exposure to morbidity particularly in old age when morbidity increases. It is estimated that "an annual toll of over half a million deaths and eight million cases of disability are from pregnancy related causes" (WHO, 1998). Nearly 40\% of women are now in the labor force around the world. Due to underrecording, the actual percentage is likely to me much higher (WHO, 1998). For millions of these under-paid and overworked women, especially those in the informal and agricultural sectors, the "double burden" of work has the net effect of adding distress and reducing their quality of life. Unfortunately, we do not have systematic studies to document the net effects of this double burden. AIDS is becoming a major risk factor for women, especially in poorer nations. Nearly one-half of 5.8 million HIV infections in 1997 were in women. Currently $42 \%$ of people living with HIV are women. The risk of HIV infection through unprotected vaginal intercourse is two to four times higher for women than men (WHO, 1998). Gender-based violence (e.g. rape, coercive sex, rape as an instrument for terrorizing people during armed conflicts) has disastrous physical and mental health consequences including: STDs, physical injury, unwanted pregnancy, post-traumatic stress, psychological disorders including depression, substance abuse, and fatal outcomes (e.g. HIV/AIDS, homicide, suicide). A recent review of 40 population-based studies across the world indicate that between $25 \%$ to $50 \%$ women become victims of physical abuse by men. Women also suffer more from globalization and urbanization impacts, especially in poorer nations. Pressures from foreign donors for "structural adjustments" have lead many local governments to reduce or eliminate many health and welfare services. This adversely affects women more than men. Finally, women's overall health and QOL are also adversely affected by cultural practices including "double burden" of risks (both at home and in work environments); feminization of poverty; female genital mutilation (FGM); early marriage; intimate violence perpetrated by men, sexual abuse and exploitation; spouse abandonment; and stresses and strains of daily living.

\section{Education}

Development studies provide overwhelming evidence of the positive effects on women's education and workforce participation on health and other aspects of quality of life (Boserup, 1971; Sen, 1990; Tinker, 1990; Moser, 1993). One in-depth study which examined the impacts of female literacy, female labor force participation, poverty (income), urbanization, and access to health care on infant mortality in India (Sen, 1990; Murthi, Guio, and Derez, 1995) revealed the predominant role of women's education on health outcome. That study showed that "the powerful effect of female literacy contrasts with the comparatively ineffective roles of, say, male literacy or general poverty reduction as instruments of child mortality reduction (Sen, 1990). The same study also examined the relative impacts of female and male education. Interestingly, the study concluded that female literacy is found to have an unambiguous and statistically significant effect on reduction of under-five mortality, even after controlling for male literacy" (Sen, 1990). The WHO also concluded that, compared to income, women's educational level, particularly the aspects of "generation and utilization of new knowledge", has produced significantly greater impacts on several health related outcomes, including mortality rates for children under five years of age, adult female and male mortality, adult female and male life expectancy at birth, and total fertility rates (WHO, 1999). The obvious conclusion from these studies is that, welfare reform that invests in women's education, better access to health care, and generation and utilization of relevant new knowledge (research and utilization of research), would have greater positive effects on health and QOL for the entire community including women, men, and children, compared to a strategy that focuses on wealth, technology, and modernization as goals of development. 


\section{Reciprocity between income, education, and health}

Socio-economic and political systems define welfare systems affecting our health status and QOL. At the same time, the health status of populations, epidemics, natural and man-made disasters, and QOL in turn affect economic productivity and development. Specifically, education, standard of living, access to health care, and distributive justice all have significant effects on our health status and QOL (Boserup, 1971; Sen, 1990; Tinker, 1990; Moser, 1993). WHO has long recognized that health development cannot be achieved by the health sector alone; there is a need to go "beyond health" interventions (multi-sector collaborations) to promote health. This reciprocal relationship between health and welfare systems requires that we carefully examine how these two systems affect each other in specific populations, and formulate policies and actions to promote the synergy between these processes.

\section{Work and quality of life (QOL)}

In addition to the quality of our personal and family life, health, job-satisfaction, and occupational hazards are some of the most important domains affecting our QOL. Most men and women work, but the primary difference between work performed by men and women is that, in general, men work outside their homes and get paid for what they do. Women, on the other hand, spend more time in bearing children, childcare, and domestic work. In addition, they often work outside to supplement family income. For their reproductive and domestic work women never get paid; for their outside work they are often underemployed, underpaid, deprived of adequate health and retirement benefits, and subjected to sexual harassment (ILO, 1999). This pattern is true in both developed and developing nations. Women are engaged in activities that are essential for bearing and rearing children and family well-being, but these activities do not produce marketable goods and services with what economists call "exchange values". Consequently, even though women often work harder than men, they do not have autonomy and control over their own lives. Ester Boserup (1971 and 1986) in her original study entitled "Women' s Role in Economic Development", pointed out that rapid modernization and the application of technology in economic development benefited men while it often increased women's work burden both as "family and casual labor". In one micro-economic analysis of power and family dynamics, Sen (1990) suggests a model of "cooperativeconflicts" which explains women's lack of "bargaining-power" in family decisions (or relative powerlessness) that is rooted in our cultures. The solution, like most complex social problems, is not an easy one; but his basic assertion is that equality in women's bargaining position will only result from removal of various forms of "unfreedoms" and enhanced empowerment of women's agency (their power and capacities) through education and social reforms. Microanalyses also suggest that quality of work significantly affects health and quality of life of individuals. Several examples of this include: psychological dissatisfaction with monotonous work, poor pay, sexual harassment and abuse, assault and rape (especially against street/slum dwellers, domestic helpers, and sex workers), inadequate day care facilities, and absence of bargaining power and access to labor unions (ILO, 1999). The list is long and familiar to most readers.

\section{Culture-related crimes against women}

Cultural crimes are those heinous offenses committed against women, often against existing laws, which are perpetuated in the name of preservation of culture or tradition and due to lesser value attached to the lives of women. These practices are deeply rooted in culture and customs and are not due to lack of development, per se; they occur in both developed and developing countries. Several major forms of cultural crimes which threaten women's lives and health include the high prevalence of female genital mutilations (FGM) in Africa and the Middle East - which is one example of culturally rooted extreme brutality against women (WHO, 1999). Each year, nearly two million girls are estimated to be subjected to FGM with a prevalence rate as high as $98 \%$ in Somalia and Djibouti and 90\% in Ethiopia and Eritrea (Toubia, 1995). The high incidence of preventable maternal mortality is another example of how the cultural devaluation of women's lives can lead to an excessive amount of preventable deaths. In one country, thousands of women become the victims of "dowry deaths" each year. Government figures show that in 1995 there were over 7,300 dowry deaths, while other estimates suggest a significantly higher level of prevalence as discussed before (Jethmalani, 1995; WHO, 1999). Exact numbers have 
not been established. Dowry deaths are unreported and, for each dowry death, many more women are severely abused. See Box 3 .

Other forms of injustices include cultural and religious practices, which are often institutionalized as the traditional norm. Examples include, laws that deprive women of their rights to vote, own and inherit property, seek employment outside the home, marriages without consent, divorcing an abusive spouse, and reproductive choice and population policy that favor survival of male child. Altering these conditions requires cultural changes and the empowerment of women. The three examples below illustrate how culture can institutionalize victimization of women in both developed and less developed countries (De Bruyn, 1995). They illustrate problems that cannot be solved by traditional development and welfare programs.

"Wife beating is an accepted custom... we are wasting our time debating the issue", comment made by a parliamentarian during floor debates on wife-beating in Papua New Guinea.

"The child was sexually aggressive" - reason given by a Canadian judge for suspending the sentence of a man who had sexually assaulted a three-year old girl.

"If a pregnant woman is found to have AIDS she should be killed so that AIDS ends with her", said a Zimbabwean parliament member during a debate on legalization of abortion.

\section{Media and Women}

The role of the media, or the role of women in the media (or lack of it), is an area of global concern. There is a global consensus that news and entertainment perpetuates gender inequality by: (1) portraying women in subordinate positions, (2) as sex objects, (3) depicting violence against women as a way of life, (4) excluding women's (audience) perspectives in programs, and (5) exclusion of women in policy-making and leadership positions in media establishments. In addition, with the increasing globalization of commercial and entertainment industries, people in poor countries are being increasingly exposed to media productions exported by richer countries and outside cultures. A UNESCO study shows that the trade of media materials with "cultural content" (printed matter, music, visual arts, movies, photography, radio, and TV) almost tripled between 1980 and 1991, from $\$ 67$ billion to $\$ 200$ billion (UNDP, 1999). Modern communication technology via satellite has expanded very rapidly; the number of TV sets per 1,000 people worldwide doubled between 1980 and 1995 from 121 to 235. Media production and sales are also becoming the monopoly of a few rich nations. For example, "for the United States, the single largest export industry is not aircraft, computers or automobiles - it is entertainment, in films and television programs" (UNDP, 1999). The impact of such rapid expansion of modern media propagating sex, violence, and hazardous lifestyle (e.g. movies, videos, TV) on third world cultures, and generation and gender role conflicts everywhere is unknown (UNDP, 1999; Kar and Acalay, 2000). Commercial media clearly is not a welfare system and democratic societies uphold the value of freedom of media. Consequently, we cannot demand that media must educate and reform our societies nor can we control the media through draconian measures. At the same time, all freedom of action and expression has its limits, which must be balanced against collective interests and utility. Rather than introducing sanctions, it is more desirable to rigorously apply two widely accepted principles for media reform: "gender equity" and the protection of minors from media violence and pornography.

\section{Strategies and models for reform}

The above discussion has led to the recognition of two universal realities -

- the circular relationship between health, education, and wealth, that is, each is both the means and end of the other and therefore improvement in one improves the other (WHO, 1996; UNDP, 1999); and 
- the vast inequality in distribution of wealth, education, and health between rich and poor countries, and the vast inequality within each country by differences in gender and social categories (e.g. class, race, religion, minority status).

The imperative of the first reality is that health development and welfare reform are interrelated. The imperative of the second reality is that inequalities adversely affect the health and well-being of billions of people, most of whom are women. The first imperative requires multi-sectoral collaboration for targeted development and welfare reform for all. The second imperative requires actions to promote distributive justice, empowerment of women (and disadvantage groups), and to remove barriers to basic rights, health care, and welfare services.

\section{Development theories and models}

Our review identified five models for development/welfare reform interventions: welfare, anti-poverty, equity, efficiency, and empowerment. The first three models emphasize reduction of poverty and more equitable distribution of resources based upon women's productive and reproductive functions to justify investment in women. The efficiency approach focuses on increased participation of women in the labor force and argues that it enhances women's status and well-being. In reality, most semi-skilled or unskilled women are employed in underpaid jobs. Critics insist that these four approaches do not address the basic cause of women's problems, which are inequality and powerlessness. Therefore they (Footnote 3 ) advocate women's empowerment as the primary model for dealing with gender inequality. It is important to note that the aim of these and other models of welfare reform are to bring about desired structural and cultural changes.

\section{Structural change}

This approach focuses on reforming specific domains of welfare systems (primarily employment, education, and health) that affect our overall quality of life. The efficiency approach is currently popular with most multinational donors and national governmental agencies. It emphasizes that increased women's participation and involvement in existing programs or "mainstreaming" women into various welfare programs (sectors) is the best way to reduce gender inequality. Consequently, the efficiency approach concentrates on the enrolment of more women in existing education, employment, and health care. Critics of structural change point out that "mainstreaming" has failed to achieve equity in women's education, employment, and income. For instance, usually when manufacturing and industrial sectors hire more women, they hire women as a source of cheap labor (to fill lowpaid and temporary positions). Increased employment of women in these situations reduces labor cost and thus increases production "efficiency" (e.g. textile and garment industry, agricultural sectors). Such mainstreaming does not offer underemployed women a decent standard of living or security. The strategy of "separate but equal programs" for women also is not very effective because these programs cannot compete with existing welfare systems that historically favor men. Finally, categorical programs may serve specific needs, but they do not remedy the fundamental problem of inequality and often make the recipients more dependent on these agencies and welfare services (Sen, 1990; Tinker, 1990; Moser, 1993; Thin, 1995; ILO, 1999; WHO, 1999; World Bank, 1999).

Development scholars and activists point to historical evidence and claim that prevalent welfare systems that perpetuate persistent inequality cannot be expected to reform themselves. A case in point is the failure of development programs in many nations to reduce inequity and control the widening gulf between the haves and have-nots. In order to reduce government spending, structural adjustments were introduced by many nations (in compliance with requirements of foreign and multinational donors). These adjustments required that national governments reduce the burden of welfare services and encourage the private sector to pick up these services and costs. This structural adjustment policy has had devastating effects on the poor and the women who need welfare services the most. It is not surprising that the scholars cited above and others, along with many feminists, insist that patriarchal systems and subordination of women are deeply rooted in culture, and that true reforms must extend beyond specific welfare reform. True reform should focus on the empowerment of women and engage in culture change to improve men's perception and attitudes toward women's rights and contributions.

\section{Empowerment theories and models}


The basic premise of the human development empowerment strategists (Boserup, Moser, Rawls, Sen and others) is that the fundamental cause underlying all social and welfare inequalities is the lack of freedom or prevalent unfair treatment of the disadvantaged, including women. Consequently, until the sources of these "unfreedoms" (Sen's term) are removed and women are empowered, a true social and welfare system will remain elusive. The Beijing Declaration and the UN Platform of Action clearly echo this position. John Rawls (1971) and Amartya Sen (1990), two eminent contemporary social philosophers, hold somewhat similar views. Rawls' theory of justice defines "justice as fairness". He also holds that, in a pluralistic society, there may never be full equality among all members on every aspect. But a just society must find a "fair" process for distributing what he calls, "primary goods" among its members. Primary goods are: (1) basic liberty, (2) freedom of movement and choice of occupation, (3) powers and prerogatives of social position, (4) income and wealth, and (5) social bases of respect. According to Rawls, fundamental fairness in distribution of these primary goods is more important than numerical equalities. Furthermore, for the sake of fairness, sometimes we must treat people differently in special circumstances (e.g. maternity leave, special privileges for the disabled). Rawls gives us a useful framework to look at important domains where reform is needed. Clearly, by Rawls' criteria, women are not treated fairly. According to his theory of justice, women deserve several special treatments (e.g. maternity leave), not as a favor to them, but as a just society's obligation to treat all with equal justice and fairness. Sen's model (1990) of "cooperative conflict" describes the conditions and processes that deprive women of their basic power and bargaining position within the family. Society also perpetuates conditions or "unfreedoms" that are deeply rooted in our culture; these conditions place women in no-win situations. Consequently, empowerment of women and fundamental culture change resulting in men's favorable perception of women and value of their contribution is the perquisite for any social reform. Reforms of specific welfare systems, in the absence of women's empowerment and culture change, will not be effective in remedying exploitation of women.

Moser (1987), a pioneer in gender studies, holds a similar ideology. She conceptualized a framework of "practical and strategic gender interests and needs" to explain and justify her theory of women's empowerment. According to Moser, practical gender interests develop in response to women's day-to-day unmet needs (e.g. food, day care, and health care). In most cultures, they (women) do not challenge the prevailing subordination of women, even though their practical needs arise directly from their powerlessness and subordination. Thus, she argues, welfare reforms, which only address specific and practical gender needs, will not reduce gender inequality. It is necessary to empower women to remove the root cause of their unmet practical needs. The pioneers in women's studies have long argued that our patriarchal system, which continues to subjugate women and deprive them of their equal rights and privileges, is the real cause of immeasurable sufferings endured by women. Therefore any reform, to be effective, must first remedy this situation by empowering and treating women equitably (Boserup, 1971; Moser, 1987; Sen, 1990; Tickner, 1995).

\section{Community and personal empowerment}

Social psychologists, community organizers, and activists tend to approach empowerment from a relatively micro (local or community) level. They define empowerment as a process through which individuals, communities, and organizations gain control over issues and problems that concern them most (Friere, 1987; Rappaport, 1987; Zimmerman et al., 1992; Wallerstein and Bernstein, 1994; Zimmerman, 1995). The aim of an empowerment movement is to enable the powerless to take proactive actions for the prevention of threats and the promotion of positive aspects of their lives. In this sense, empowerment is the means and QOL is the end. However, empowerment and QOL have a synergic and dynamic relationship; today's end may be tomorrow's means. For instance, a job-training program can enhance employability of a poor, unemployed woman; this process also empowers or enables her to obtain paid employment. A new job with personal income and health care benefits in turn may enhance her status within her family and QOL for herself and her family. At the same time, this new job may offer her options for future advancement and allow her to join an organized labor union, which may further empower her to protect her job security. Empowerment itself, similar to freedom of choice, should be a positive life goal. Empowerment is a multilevel construct, and therefore, analysis of empowerment methods and outcomes should be directed at three interdependent levels. These three levels are (1) individual or psychological empowerment (PE), (2) community empowerment (CE), and (3) organizational empowerment (OE) (Rappaport, 1984; Rothman and Tropman, 1987; Zimmerman et al., 1992; Israel et al., 1994; Wallerstein and Bernstein, 
1994). PE aims at the enhancement of individuals' "critical consciousness" (Friere, 1968; Friere, 1974; Friere, 1987), belief in self-efficacy, awareness and knowledge of the problems' source and the solutions, and personal competency for proactive actions to deal with the problems adversely affecting their QOL. CE focuses on the enhancement of a community resource base including leadership development, communication systems, community support and network needed to mobilize community assets and resources to address common concerns. OE aims at the creation or enhancement of a power base and resources of community-based organizations (CBOs), including voluntary organizations, unions, associations, and cooperatives to better protect, promote, and advocate priorities of the powerless.

Based upon the source of leadership, empowerment movements may be classified into two categories. The first is self-organized empowerment movements led by the victims against their oppressors or abusers with support from powerful outside allies. But the primary actors and leaders are the victims themselves. (e.g. National Organization for Women (NOW), International Planned Parenthood Federation (IPPF), and Mothers Against Drunk Driving MADD). In contrast, induced empowerment movements are organized and led by concerned professionals and leaders from outside the community of the victims. (e.g. Grameen Bank, SEWA, and Women's Action Research and Legal Action for Women (WARLAW)). Both self-organized and induced empowerment movements often share common philosophies, goals, and even operational methods. In practice, while the induced movement tends to be guided by a pre-designed theory and ideology, self-organized empowerment movements tend to be less ideological and depend more on the methods and resources which are effective and available to the public. Our review of literature on community organization and empowerment identifies five models that have induced empowerment movements. The Brazilian educator Paulo Freire (Friere, 1968; Friere, 1974; Friere, 1987), developed and popularized a unique strategy for mobilizing the oppressed through "education for critical consciousness". His central premise is that oppressed people are not fully conscious of the true source of their oppression and the potential they have to bring about a desirable change in their living condition. Community organizers serve as educators in the true sense of the word and through a two-way enduring communication and education process, the oppressed mass is awakened, energized, and mobilized for social action. Alenski (1962 and 1971) concentrated his work on labor conflicts and urban problems. He holds that "winnable confrontations" are essential to empower the abused and reduce the power gap between them and their abusers. Well-organized unions, collective bargaining, and confrontations are the methods of choice in this approach. Coleman (1988) and McKnight (1978 and 1997) believe that true empowerment is based upon effective "mobilization of community assets." Every community has valuable assets or capitals and by mobilizing these effectively and collectively, communities can solve their problems and become empowered. The fourth approach uses micro-enterprise and cooperatives for income generation and economic empowerment by poor women; their added income and their capacity to earn empower them, promote their quality of life and status with their family and community (e.g. Grameen Bank, Bangladesh and Self-Employed Women's Association (SEWA)). The fifth model is based upon legal activism and social action litigation (SAL). The effective campaign against dowry deaths in India is a good example of SAL (Jethmalani, 1995). It uses a systematic surveillance of the abused and the enforcement of existing laws against abusers, legal reforms, and the development of organizations to sustain the campaign. These models were developed and implemented by concerned social activists who came from outside the communities of the victims. They were deeply concerned and were deeply committed the cause of the poor and the powerless; at the same time they were guided by a theoretical framework that is reflected in the strategies used by them.

\section{Women's Self-Organized Empowerment Movements: A Meta-Analysis}

The remainder of this paper is dedicated to a review of strategies and methods used by successful self-organizing empowerment movements by women for themselves. The objective is to review the lessons learned from our meta-analysis of 80 exemplary case studies of empowerment movements for powerless women led by women and their implications for policy and research. The details of our theoretical framework, methodology, and initial findings (based on the first 40 case studies) are presented elsewhere (Kar and Acalay, 2000). See Box 4.

\section{Study Methodology}


In order to achieve the objective of answering the questions: can and do powerless women undertake successful grassroots movements; and if yes, how do they accomplish this, we used the following methodology: (1) literature review, (2) content analysis, and (3) meta-analysis. We initiated a literature review of women's empowerment movements from the past two decades in order to identify suitable cases for analysis (Selliah, 1989; Sen, 1990; Tinker, 1990; Afshar, 1991; Russell, 1991; Shivakumar, 1991; Stolen and Vaa, 1991; Anand, 1992; ESCAP, 1992; Rose, 1993; Young et al., 1993; CISFAN, 1994; Martens and Mitter, 1994; Bornstein, 1996; Burgos and Debray, 1996; Pilisuk, McAllister, and Rothman, 1996; Kar, Pascual, and Chickering, 1997; Afshar, 1998; Beckless, 1998). In addition to an extensive bibliographic search (MELVYL and ORION), we performed telephone and personal interviews with members of national and international agencies, reviewed university course syllabi dealing with community organizations and development, networked and consulted with knowledgeable professionals and scholars, and searched websites of relevant organizations to identify written materials on potential case studies.

\section{Selection criteria}

The selected cases fulfilled all of the following five criteria -

1. Availability of reliable written descriptions: Accounts of organizations and social movements were culled from authoritative published reports, articles, books, etc., from credible publishers and/or organizations, which had adequate descriptions of the important seven dimensions used in our content analysis.

2. Representativeness: The case studies represented both economically developed and less developed nations.

3. Domains: The case studies represented the four domains of QOL (human rights, equal rights, development, and health promotion).

4. Sustainability: The case studies were successful and had survived long enough to achieve the specified goals in whole or in part. Most cases were still in operation.

5. Effectiveness: The case studies selected were successful in achieving their objective, have gained national and international recognition, and are considered models for other programs (or have been adopted by other programs).

\section{Content analysis}

The literature search identified 80 successful case studies from economically developed and less developed nations' (Footnote 4) which met the above criteria. From each of these case studies we were able to extract basic and comparable information on seven predetermined categories or dimensions -

1. Identifiers: location ('more' or 'less' economically developed countries), year of founding

2. Problem: in measurable terms and at baseline before intervention(on the four domains)

3. Leadership: leadership of the movement; organized, led, and/or sustained by women

4. Methods: specific programs and activities performed by the movement

5. Partners/Opponents: supporters or adversaries to movement

6. Context or Macro-environment: larger socio-political environment and external events affecting the movement

7. Impact: outcome or effect on actor's and beneficiaries QOL including current status of movement/action; effect on community

\section{Meta-analysis}

Once the content analysis was complete, a meta-analysis was then carried out to compare and analyze the findings from the individual content analyses. These 80 case studies are examples of successful empowerment movements initiated by women and for women (often by the victims). The case studies were chosen from the four domains that affect their quality of life: (1) Human rights (13 cases); (2) Equal rights (9 cases); (3) Disease prevention and health promotion (50 cases); and (4) Economic development/micro-enterprise ( 8 cases). We combine qualitative and quantitative methods in this meta-analysis. The four stages included for the meta-analysis were -

Content analysis of each case study to extract data on six analytical dimensions:

(i) nature of the problem

(ii) impetus or leadership 
(iii) empowerment methods used

(iv) supporters and opponents

(v) macro-environment (political and cultural)

(vi) status and outcomes of the movement

The analysis consisted of analysis of data from all cases along these six analytical dimensions and comparisons of empowerment methods used by: (i) four domains, (iii) richer and poorer nations, (iii) health and non-health movements, and (iv) construction of a multi-phase empowerment model which integrates the major findings into a conceptual framework for future research and policy deliberations. The model also identifies the instrumental support at various phases which enabled these movements to begin, mature, and become institutionalized (Kar and Acalay, 2000).

\section{Data analysis and Major Findings}

Cochran's Q test (Cochran, 1950) was used to determine if the frequency of use of the seven empowerment methods (see box below) varied significantly across the case studies. This test is used for a block design when the responses are all dichotomized. The observations in different blocks are assumed to be independent, but the responses within each block may be related. The blocks are the 80 case studies; the observations are the use or non-use of each method of empowerment by these cases.

The obvious but important finding is that powerless women can and do initiate and lead successful movements against their abusers and they often do so under the most adverse conditions. Numerous case studies of successful movements support this finding (Jenness, 1991; Basu, 1995; Afshar, 1998; SEWA; MADD). They succeed not because of, but in spite of, help from those who controlled the systems. They did so with: (1) their strong determination; (2) substantive help and support from concerned professionals, civic leaders and public, and organizations dedicated to their cause; and (3) effective use of empowerment methods. The implication of this finding is that we, in the helping professions, have an important role to play in women's health and welfare reform. The meta-analysis enabled us to identify seven empowerment methods, which are most frequently used by these successful empowerment movements. These seven methods are encapsulated in our EMPOWER acronym; the box below presents the frequency and ranking of these seven methods (in parentheses). One notable overall finding is that there are significant differences in the frequencies of use of these seven EMPOWER methods ranging from $88 \%$ of the movements using enabling services to $28 \%$ movements using work/job/income generation (Cochran's Q test $=86.58, \mathrm{df}=6$; alpha $=1 \%$; Asymp. Sign $=.000)$. It is not surprising that enabling and relief services are the top priorities of these movements. Legal protection, public education for generating public, pressures on decision makers, and organizational support (technical support from unions, cooperatives), closely follow. Empowerment training, leadership development, and proactive media use were common among one-half of these movements. Job training and micro-enterprises were used least frequently.

When the case studies of developed and developing countries are compared, interesting similarities and differences occur. Cases from developed and developing countries used the following four methods of empowerment with equal frequency: (1) Enabling services (89\% and $85 \%$ respectively); rights protection and reform (74\% and $77 \%$ respectively), organizing unions/associations, and partnerships $(70 \%$ and $71 \%$ respectively); and empowerment training and leadership development (54\% and 53\% respectively). Developed countries used media ( $67 \%$ versus $24 \%$ ) and public education methods ( $85 \%$ versus $59 \%)$ more frequently. Poor countries used these two methods less frequently perhaps because both methods have indirect and delayed effects on the immediate problems. In addition, mass media use is very expensive; for example a 30 -second primetime TV spot in the United States costs between 0.25 and 2 million dollars. In poorer countries, women and their sympathizers do not have ready access to mass media. Cases from developed countries, more than twice as often used micro-enterprise than developed countries ( $41 \%$ versus $17 \%$ ); although more is needed in poor countries, this approach requires start up funds, which are not easy to obtain. The initial problems Professor Yunus encountered in raising start-up funds for the Grameen Bank project is a case in point (Prigogine and Stengers, 1994). All successful movements needed and received core support from powerful individuals outside the communities. Support came from various segments of society: concerned professionals, leaders and politicians, 
NGOs, academics, mass media, and organized unions and associations. Movements based upon basic human needs and organized by women and mothers (who are not perceived as a real threat to the system) generate wider public support for reform. Another significant finding is that, a comparison of the use of seven EMPOWER methods for health promotion versus non-health promotion (human rights, equal rights, and micro-enterprise) movements showed no statistical differences. This finding suggests that effective use of these seven EMPOWER methods is essential for the success of desperate empowerment and welfare reform movements regardless of the specific goals these programs hope to achieve.

\section{Discussion}

Based upon the quantitative and qualitative findings, the following ten propositions have been constructed to serve as guidelines for planning community-based empowerment and welfare reform in disenfranchised populations -

1. Motivation of women and mothers to prevent harm to their children and family is a strong driving force for reform; this social capital should be harnessed for welfare reform.

2. A struggle for survival needs and basic human rights is likely to generate wider public support.

3. Struggles led by non-political and political women for survival and basic human rights are likely to generate wider local, national, and international support.

4. Participation is empowering; women's participation in any aspect of a movement empowers them.

5. CORE (Community, Organization, Resource, and Empowerment Education) support at the early phase of a local initiative is essential in its ultimate success.

6. Enabling services, rights protection, and technical assistance empower women to resist abuse and sustain their struggle.

7. Non-formal education and leadership training are essential for organizational empowerment in support of reform movements.

8. Media use, support, and advocacy can significantly promote public opinion and pressure for reform.

9. External recognition is essential for institutionalization and wider adoption of effective movements.

10. A non-violent empowerment movement for a just cause is likely to gain wider public support.

\section{A Multi-Step Empowerment Model}

The meta-analysis revealed a common pattern through which these reform movements begin, mature, and become institutionalized. Based upon our key findings, a four-step empowerment model has been constructed that describes the life-cycle of these movements. These steps are:

(1) Initial condition: when persistent sufferings and abuse motivate women for reform. At this step organized reform does not exist. The condition is akin to the "initial condition" of chaos and complexity theory according to which at this phase "small inputs can yield huge, startling effects" (Prigogine and Stengers, 1994)

(2) Initial individual action: is usually taken by a few desperate and bold individuals. These actions serve as small input, which energizes others who are dissatisfied, for collective action. In all but one case (Grameen Bank) the initial action or "small input" came from the affected women and in some cases from women in power who cared

(3) Organized movement: begins with planned collective action with CORE (community, organizations, resources mobilization, and empowerment education) support. Effective partnership, local leadership and professionals play important roles

(4) Institutionalization: initial success of organized movement, external support, and recognition helps legitimize and sustain a movement. It becomes institutionalized as a new program or as a part of existing movements, union, coalition, or association Figure 2.

At each step, a movement benefits from different types of support from various sources. Partnership building, technical assistance, and external recognition play important roles in the evolution of a sustainable movement.

\section{Conclusion}


This paper reviewed the limitations of and key issues in human development programs (education, economy, health and welfare, justice, and socio-cultural reforms) that affect women's health and QOL. Models of welfare and health systems reforms were reviewed to identify linkages and synergies among them. Evidence suggests that traditional human development programs and health care reforms tend to bypass those who need the services most; these programs do not address the basic problems of the poor and powerless: i.e. excessive distress, deaths, disabilities, and lack of access to services caused by gender inequality and powerlessness. Consequently, an effective human development reform requires a dual approach including - (a) targeted health and welfare systems reform to meet urgent and unmet needs in populations, and (b) women's empowerment to reduce life threatening gender inequalities and enhance quality of life for families and communities (we are not advocating armed revolutions which may or may not establish a just society). Women's empowerment is also justified as an utilitarian necessity; healthy and empowered women are an important social capital because they are the primary care givers in most communities, and investment in women results in greater benefits to their children and family. Major empowerment theories and models have been discussed. These theories and models tend to be gender insensitive and do not elaborate on empowerment issues and methods that are most unique to women globally. The paper subsequently focused on models and methods of women's empowerment for better health and quality of life. Empowerment movements can be categorized into two types: (1) induced empowerment movements that are initiated and led by people (e.g. professionals, activists, politicians) from outside the community of victims; and (2) self-organized empowerment movements that are initiated and led by the powerless women themselves. The paper subsequently reviewed self-organized women's empowerment movements to examine whether and how powerless women organize movements that empower them and enhance health and quality of life for themselves, their families, and communities. It reviewed the key findings of a meta-analysis of 80 effective empowerment movements, initiated and led by women, from developing and developed countries. Meta-analysis identified seven effective empowerment methods (acronym EMPOWER) that are frequently used by these successful movements and a four-step life cycle of these movements. A successful movement always involves an effective leadership partnership with diverse groups each having distinct roles defined by their own values, assets, and constraints. The central challenge before us is to build true partnerships for health and welfare reforms, with clearly defined roles and responsibilities of those who are a part of that partnership.

\section{Footnotes}

1. For more information on Human Development Index (HDI), Gender Development Index (GDI), Gender Empowerment Measures (GEM), and Human Poverty Index (HPI 1 \& 2) see UNDP/HDR, 1999.

2. We adopt the expression "Persistent Inequalities" from the title of the book edited by Tinker (1990).

3. Both women and men can be effective advocates of women's perspectives; the critical requirement is not the gender of the advocate but ratehr the extent to which she/he is knowledgeable and is dedicated to the cause. Indeed, all successful movements require active involvement of victims and support from others who care for the victims.

4. We used the UN classification of "economically developed" and less developed nations. We recognize, however, that many countries, which have maintained theri national identity and sustained their ancient heritage 4 for several millenia (e.g. Egypt, China, Greece, and India) were culturally and politically advanced thousands of years before the birth of many modern, "developed" nations.

\section{Acknowledgements}

We wish to thank the Kellogg International Fellowship Program in Health (KIFPH) and the Michigan State University for sponsoring the parent project on development of health promotion indicators that led to our subsequent research on women's empowerment for health promotion. We wish to thank the HRSA (USPHS) for sponsoring our research on women's empowerment that provided the data used in this paper.

\section{References}

Afshar, H.1991. Women, Development and Survival in the Third World. New York: Longman. Afshar, H.1998. Women and Empowerment: Illustrations from the Third World. London: McMillan. 
Alinsky, S.1962. Citizen Participation and Community Organization in Planning and Urban Renewal. Chicago, IL:Industrial Area Foundation.

Alinsky, S.1971. Rules for Radicals. New York, NY:Vintage.

Anand, A.(Women's Feature Service).1992. The Power to Change; Women in Third World

Redefine Their Environment. Atlantic Heights, NJ:Zed Books.

Anon. 1991. Quality of Life. Lancet. 338:350-351.

Basu, A.1995. The Challenge of Local Feminisms: Women's movements in global perspective. Boulder, CO:Westview Press.

Beckles, M.1998. Strange Bedfellows: Women and Gender Stereotypes in Argentine Politics. Master of Arts Thesis. Los Angeles:UCLA Latin American Studies Center.

Bornstein, D.1996. The Price of a Dream. New York:Simon \& Schuster.

Boserup, E.1971. Women's Role in Economic Development. London:Allen \& Unwin.

Also see Tinker I. 1990:14-26.

Boserup, E.1986. Women's Role in Economic Development. London:Allen \& Unwin.

Also see Tinker I. 1990:14-26.

Burgos, R., and E. Debray.1996. Rigoberta Menchu: An Indian Woman in Guatemala. New York:Verso.

Center for Integrated Services for Families and Neighborhoods (CISFAN).1994. Strategies for Distressed

Neighborhoods. Sacramento, CA:CISFAN.

CHANGE/JHU.2000. Violence Against Women Report. Baltimore:Johns Hopkins University.

Coleman, J. 1988. Social capital in the creation of human capital. American Journal of Sociology. (Supplement).

94:S95-S120.

De Bruyn.1995. In advancing womens status. Amsterdam:Royal Tropical Institute (KIT).

ESCAPE.1992. "Integration of Women's Concerns into Development Planning in Asia and the Pacific". New

York:United Nations.

Freire, P.1968. Pedagogy of the Oppressed. New York:Seabury Press.

Freire, P.1974. Education: Practice of Freedom. UK, Writers and Readers Publishing

Cooperative.

Freire, P.1987. Education for Critical Consciousness. New York:Seabury Press.

Harvard University.2000. Global Burden of Disease Project.

International Labor Organization (ILO).1998-1999. World Employment Report. (Footnote 1)

International Labor Organization (ILO).1999. World Employment Report.

Israel et al.1994. Health Education and Community Empowerment: Conceptualizing and

Measuring Perceptions of Individual, Oganizational, and Community Control. Health Education Quarterly.

21(2):149-169.

Jenness, V.1991. From Sex as Sin to Sex as Work: COYOTE, organizational Legitimization and the

Contemporary Prostitutes' Rights Movement. Doctoral Thesis. Santa Barbara:Univ. of California.

Jethmalani, R.1995. Kali's Yug: Empowerment, Law, and Dowry Deaths. Women's Action

Research and legal Action for Women (WARLAW), New Delhi, India:Har-Anand Publications.

Kar, S.B., and E. Berkanovic.1987. "Indicators of Behaviors Conducive to Health Promotion" in Measurement in

Health Promotion and Protection, Abelin, T., et al (Eds) WHO/EURO. Pub. Series No. 22:267-281.

Kar, S.B., W. Coleman, J. Bertolli, and E. Berkanovic.1988. "Indicators of Individual and Community Actions for Health Promotion," Health Promotion. 3(1) Special supplement:59-66.

Kar, S.B.1990. Primary Health Care: Implications for Medical Professions and Education, Academic Medicine, 65/5:301-306.

Kar, S.B., C. Pascual, and K. Chickering.1997. Empowerment of Women for Education and Health Promotion: A Meta Analysis" paper presented at the 47th Annual meeting of the Comparative International Education Society (CIES), Mexico City, March 19-23.

Kar S.B.1999. Substance Abuse Prevention: A Multicultural Perspective. New York: Baywood Publishing.

Kar, S.B., C. Pascual, and K. Chickering.1999. Empowerment of Women for Health Promotion: A Meta Analysis. Social Science and Medicine. 49(11):1431-1460.

Kar, S.B.2000. "Better Health and Welfare Systems: Women's Perspectives," International Meeting on Women and Health, WHO Kobe Center.

Kar, S.B., and R. Acalay.2000. Health Communication: A Multicultural Perspective. Thousand Oaks,CA:Sage Publications. 
MADD: Mothers Against Drunk Driving Website, http://www.madd.org

Martens \& Mitter.1994. Women in Trade Unions: Organizing the Unorganized. Geneva:

International Labor Organization.

McKnight, J.L.1978. Community health in a Chicago slum. Development Dialogue. 1:62-68.

McKnight, J.L.1997. Keynote address on resource-based community development. Conference on Community

Campus Partnerships for Health (CCPH). San Francisco, CA:CCPH:UCSF.

Moser. CON.1987. Women, Human Settlements, and Housing: A Conceptual Framework for

Analysis and Policy-Analysis. In Moser C. \& L. Peake (Eds); Women, Human Settlements, and Housing.

London:Tavistock.

Moser.1993. CON. Gender Planning and Development. London:Routledge.

Murthi, Guio, and Derez.1995. "Mortality, Fertility, and Gender Bias in India", Population and Development

Review. Vol. 12(December).

Pilisuk, M., J. McAllister, and J. Rothman.1996. Coming together for action: the challenge of contemporary grassroots community organizing. Journal of Social Issues. 52(1):15-37.

Prigogine, I., and I. Stengers.1994. Order out of Chaos. In Forward by Alvin Toffler. New York:Bantam, xvi. Rappaport, J.1984. Studies in empowerment: Introduction to the issue. Prev. Hum. Serv. Vol. 3.

Rappaport, J.1986. "Collaborating for Empowerment: Creating the language for mutual help". New Populism: the Politics of Empowerment. Boyte, H.C., and F. Fiessman (Eds). Philadelphia, PA:Temple University Press. p. 10.

Rappaport, J.1987. Terms of empowerment/examples of prevention: Toward a theory for community psychology. American Journal of Community Psychology. 15:121-148.

Rawls, J.1971. Social Unity and Primary Goods. In: A Theory of Justice, Cambridge, MA:Harvard University

Press.

Rose, K.1993. Where Women Are Leaders: The Story of SEWA (Self-Employed Women's Association). New Jersey:Humanities Press.

Rothman \& Tropman.1987. Models of community organization and macro practice perspectives: their mixing and phasing. In: Cox, F.M. et al., (Eds). Strategies of Community Organization (4th ed.). Itasca, IL:Peacock. 3-26.

Russell, D.E.H.1991. Lives of Courage: Women for a New South Africa. USA:Basic Books.

Selliah, S.1989. The Self Employed Women's Association. Ahmedabad, India and Geneva:ILO.

Sen, A.1990. Gender and Cooperative Conflicts, In: Tinker I. Editor, 123-149.

Sen, A.1999. Development as Freedom. New York:Alfred A. Knopf.

SEWA, Self-Employed Women's Association Website: http://www.sewa.org.

ShivaKumar.1991. UNDP's Human Development Index: A computation for Indian States.

Economic and Political Weekly. October 2.

Stolen \& Vaa.1991. Gender and Change in Developing Countries. Oslo:Norweigan Univ. Press.

Thin, N.1995. Advancing Women's Satus: Gender, Society, and Development: Women and Men Together.

Amersterdam:Royal Tropical Institute (KIT), 22-36.

Tickner, J.A.1995. Gender in International Relations: Feminist Perspective on Achieving Global Security. New

York:Columbia University Press.

Tinker, I.1990. Persistent Inequalities: Women and World Development. New York:Oxford University Press.

Toubia, N.1995. Female Genital Mutilation: a Call for Global Action. New York:Rainbow.

United Nations Development Program (UNDP).1999. Human Development Report. New York: UNDP.

Wallerstein, N., and E. Bernstein.1994. Health education and community empowerment:

conceptualizing and measuring perceptions of individual, organizational and community control. Health

Education Quarterly.21(2):141-148.

World Bank.1999. World Development Report.

World Bank.2000. World Development Report.

World Health Organization (WHO).1995. Health Related Quality of Life.

World Health Organization (WHO).1996. Investing in Health Research and Development. Report of the Ad Hoc Committee on Health Research Relating to Future Intervention Options. Geneva:WHO.

World Health Organization (WHO).1998. Gender and Health: Technical Paper.

World Health Organization (WHO).1998. Quality of Life. Center, Michael Buenafe, Instrument Dissemination

Coordinator, University of Washington, Box 357660, Seattle, WA 98195.

World Health Organization (WHO).1999. Health and Development in the 20th Century. Geneva:WHO. 
Young et al.1993. Women at the Center: Development Issues and Practices for the 1990's. West Hartford, CT:Kumerian Press.

Zimmerman, M. et al.1992. Further Explorations in Empowerment Theory: An Empirical Analysis of Psychological Empowerment. American Journal of Community Psychology. 20(6):707-727.

Zimmerman, M.1995. Psychological Empowerment: Issues and Illustrations. American Journal of Community Psychology. 23(5):581-599.

\section{Footnote}

1 Latest data cited from UN agencies (UN, UNDP, WHO, ILO, UNICEF, World Bank, UNESCO, etc.) were downloaded from their respective websites. 